\title{
Differences and similarities
} of high-resolution computed tomography features between pneumocystis pneumonia and cytomegalovirus pneumonia in AIDS patients

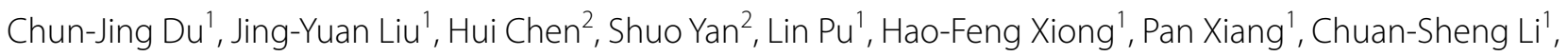
Ming Zhang ${ }^{1}$, Ru-Ming Xie${ }^{2}$, Bu-Dong Chen ${ }^{2 *}$ and Ang $\mathrm{Li}^{i^{*}}$ (D)

\begin{abstract}
Background: Accurately differentiating pneumocystis from cytomegalovirus pneumonia is crucial for correct therapy selection in AIDS patients. Hence, the goal of this study was to compare the computerized tomography (CT) features of pneumocystis pneumonia and cytomegalovirus pneumonia in AIDS patients and identify clinical hallmarks to accurately distinguish these two pathologies.

Methods: A total of 112 AIDS patients (78 with pneumocystis pneumonia and 34 cytomegalovirus pneumonia) at Beijing Ditan Hospital from January 2017 to May 2019 were included in this study. Two experienced chest radiologists retrospectively reviewed $\mathrm{CT}$ images for 17 features including ground-glass opacity, consolidation, nodules, and halo sign. Binary logistic regression analyses were conducted to identify the significant parameters that distinguished pneumocystis pneumonia from cytomegalovirus pneumonia. Correlations were analyzed by Pearson or Spearman correlation analyses. Result were considered significant if $P<0.05$.

Results: The presence of consolidation, halo signs, and nodules (all $P<0.05$ ) were significantly more frequent in patients with cytomegalovirus pneumonia than in those with pneumocystis pneumonia. Small nodules (32.5\% in cytomegalovirus pneumonia, $6.41 \%$ in pneumocystis pneumonia, $P<0.001$ ) without perilymphatic distribution were particularly common in patients with cytomegalovirus pneumonia. Large nodules were not found in any of patients with cytomegalovirus pneumonia. The presence of ground-glass opacity, reticulation, and bronchial wall thickening (all $P>0.05$ ) were common in both groups.
\end{abstract}

Conclusions: Analysis of consolidation, nodules, and halo signs may contribute to the differential diagnosis of pneumocystis pneumonia or cytomegalovirus pneumonia. However, some CT features considered typical in one or

\footnotetext{
*Correspondence: budongchen@sina.com; liang@ccmu.edu.cn

1 Department of Critical Care Medicine, Beijing Ditan Hospital, Capital

Medical University, No. 8 Jingshundong Street, Chaoyang District, Beijing 100015, China

${ }^{2}$ Department of Radiology, Beijing Ditan Hospital, Capital Medical University, No. 8 Jingshundong Street, Chaoyang District, Beijing 100015, China
}

(c) The Author(s) 2020. Open Access This article is licensed under a Creative Commons Attribution 4.0 International License, which permits use, sharing, adaptation, distribution and reproduction in any medium or format, as long as you give appropriate credit to the original author(s) and the source, provide a link to the Creative Commons licence, and indicate if changes were made. The images or other third party material in this article are included in the article's Creative Commons licence, unless indicated otherwise in a credit line to the material. If material is not included in the article's Creative Commons licence and your intended use is not permitted by statutory regulation or exceeds the permitted use, you will need to obtain permission directly from the copyright holder. To view a copy of this licence, visit http://creativecommons.org/licenses/by/4.0/. The Creative Commons Public Domain Dedication waiver (http://creativeco mmons.org/publicdomain/zero/1.0/) applies to the data made available in this article, unless otherwise stated in a credit line to the data. 
other diseases appear with similar frequency in both cohorts of AIDS patients. CT features are potentially useful for the differential diagnosis of pneumocystis pneumonia and cytomegalovirus pneumonia in AIDS patients.

Keywords: Diagnostic imaging, Pneumocystis pneumonia, Cytomegalovirus pneumonia, HIV/AIDS

\section{Background}

AIDS remains one of the most widespread infectious diseases and a major global health concern in resourcepoor settings [1, 2]. According to United Nations Programme on HIV/AIDS, an estimated 1.7 million people (1.2-2.2 million) acquired HIV worldwide in 2019, still three times higher than 500000 milestone set for 2020 [3]. Pneumocystis jirovecii pneumonia (PJP) and cytomegalovirus pneumonia (CMV-P) are the most common infectious complications in patients with AIDS $[4,5]$. PJP mortality rates approach $10-20 \%$ in treated patients and up to $100 \%$ in untreated patients [6], while up to $70 \%$ of CMV-P patients succumb to disease if diagnosis is delayed $[7,8]$. Both types of pneumonia have similar clinical symptoms and signs, including fever, unproductive coughing, hypoxemia, and dyspnea. But therapeutic approaches are drastically different due to intrinsic characteristics of the infectious agents. Thus, identifying the pathogenic agent is crucial for diagnosing and initiating appropriate therapies.

The diagnosis of PJP and CMV-P is usually established with identification of $P$. jiroveci and cytomegalovirus inclusion bodies in lung biopsy or sensitive immunocytochemical methods in bronchoalveolar lavage (BAL) fluid [9-12].

Despite current advances in diagnostic methods, the diagnosis of both types of pneumonia is still challenging. Microbiological confirmation is frequently invasive and difficult to obtain, which delays diagnosis and therapy [13]. Furthermore, the absence of microbiological evidence and negative results of serum antibodies are not reliable evidence to rule out pulmonary infection [14]. Imaging, especially high-resolution computed tomography (HRCT), which is fast, non-invasive, and more specific and sensitive than X-rays in detecting early and small lesions, represents a vital tool for guiding the diagnosis and therapeutic progression in patients with pneumonia [15]. To our knowledge, no study directly compared HRCT features between PJP and CMV-P in AIDS patients. Thus, incorporating the radiographic features into the clinical report may help narrow the differential diagnosis. The purpose of this study was to compare pulmonary HRCT features of PJP and CMV-P in AIDS patients and identify clinical hallmarks to accurately distinguish these two pathologies.

\section{Methods}

Patients and data collection

The institutional ethics committee of Capital Medical University affiliated Beijing Ditan Hospital approved this study and informed consent was waived because of its retrospective nature. HRCT scans were reviewed in 112 AIDS patients with confirmed PJP and CMV-P treated at Beijing Ditan Hospital from January 2017 to May 2019. All patients received bronchoscopy, performed serological and bacteriological examinations were included, and cases with existing co-infections were excluded from the study. The study comprised 78 patients with PJP and 34 patients with CMV pneumonia. Diagnosis of PJP was confirmed by symptoms of infection (fever, cough with or without sputum, leukocytosis or leukopenia) with identification of $P$. jiroveci by silver stain or Periodic Acid-Schiff stain in a bronchoscopy specimen. CMV-P cases were defined by detailed clinical evidence of infection (fever, cough with or without sputum, leukocytosis or leukopenia) with definitive BAL results of fluorescence quantitative PCR. HRCT images selected were the closest to the date of positive BAL diagnostic.

\section{CT examinations}

The thorax CT examinations were performed on a 256-detector row spiral CT scanner (Philips, iCT, Holland), or a 64-detector row spiral CT scanner (GE, Lightspeed VCT, USA). The patient was in the supine position and CT scans were performed at the end of inspiration. The scanning was set at energy of $120 \mathrm{kV}$ and automatic current based on body weight. Images were obtained at $5 \mathrm{~mm}$ thickness and $5 \mathrm{~mm}$ interval, with pitch of 1.0 (iCT) or 0.8 (VCT) throughout the chest. The images were reconstructed with high spatial resolution algorithm into $1.0 \mathrm{~mm}$ (iCT) or $0.625 \mathrm{~mm}$ (VCT) thickness. Images were interviewed at window settings suitable for assessing lung parenchyma (window width: 1000-1500 HU; window level: -600$-700 \mathrm{HU}$ ) and mediastinum (window width: 400-500 HU; window level: $30-40 \mathrm{HU}$ ).

\section{Interpretation of images}

The CT images on the medical diagnosis screen were reviewed independently in a random order by two 
experienced chest radiologists blinded to patients' clinical information. Final conclusions on the features were reached by unanimous consensus.

According to glossary of terms for thoracic imaging $[16,17]$, CT features were categorized as (a) consolidation; (b) ground-glass opacity (GGO); (c) mosaic perfusion; (d) crazy-paving pattern; (e) nodule; (f) tree-in-bud sign (TIB); (g) halo sign; (h) bronchial wall thickening; (i) reticulation; (j) mediastinal /hilar lymph node (LN) enlargement; (k) pleural effusion; (l) cavity; and (m $12 l^{*}$ roman $11 \backslash^{*}$ roman) cyst.

GGO appeared as an area of hazy increased opacity without obscuring bronchial and vascular margins. Consolidation appeared as an area of increased attenuation that obscured the margins of underlying vascular. When consolidation and GGO were both presented in an image, the predominance of the consolidation or GGO (Cons/ GGO predominance) was recorded as consolidation predominance, GGO predominance, or equal predominance; and their distribution was classified as segmental, non-segmental, or lobular. The crazy-paving pattern appeared as any superimposition of the intralobular interstitial or interlobular thickening within the GGO. The mosaic pattern was defined as patchwork of regions with heterogeneous attenuation. Nodules were defined as a rounded or irregular opacity with well or poorly defined morphology. The size of nodules was classified as micro $(<3 \mathrm{~mm})$, small $(3-10 \mathrm{~mm})$, or large $(>10 \mathrm{~mm})$ and their distribution were recorded as perilymphatic, centrilobular, or random. The tree-in-bud sign (TIB) represented centrilobular branching structures that resemble a budding tree. The halo sign was a GGO surrounding a nodule or mass.

\section{Statistical analysis}

Data were analyzed using SPSS 19.0 software package (IBM, Chicago IL, USA). Normal distributed variables were analyzed with Student's $t$-test. Non-normal distributed variables were compared by Kruskal-Wallis test. Categorical variables were analyzed by the Fisher's exact test and the chi-square $\left(\chi^{2}\right)$ test. Binary logistic regression analyses were conducted to identify the significant parameters that distinguished PJP from CMV-P. Correlations were analyzed by Pearson or Spearman correlation analyses. Result were considered significant if $P<0.05$.

\section{Results}

Baseline characteristics of the patients

Patients demographics and clinical settings are shown in Table 1. No differences in age, gender, weight, and transmission route $(P>0.05)$ were found in PJP and CMV-P cohorts. In terms of inflammation, there was no significant difference in leukocyte counts $(P=0.22)$ and C-reactive protein $(P=0.75)$ between both groups, however, the neutrophil percentage in PJP patients was higher than in CMV-P group $(P=0.01)$, and the lymphocyte percentage in CMV-P was higher than in PJP group $(P=0.02)$. In addition, the HIV viral loads were significantly higher in PJP than in CMV-P $(P=0.02)$ while no differences were found in $\mathrm{CD} 4^{+} \mathrm{T}$ cell counts $(P=0.28), \mathrm{CD}^{+} \mathrm{T}$ cell

Table 1 Characteristics of AIDS patients with Pneumocystis jirovecii pneumonia and cytomegalovirus pneumonia

\begin{tabular}{|c|c|c|c|}
\hline & PJP $(n=78)$ & CMV-P $(n=34)$ & $P$-value \\
\hline Age (years), median (IQR) & $33(29,45)$ & $38(29,48)$ & 0.12 \\
\hline Male, $n(\%)$ & $75(96.15)$ & $33(97.06)$ & 0.81 \\
\hline Weight (kg), mean(SD) & $64.05(11.20)$ & $62.82(9.99)$ & 0.58 \\
\hline Transmission route, $n(\%)$ & & & 0.41 \\
\hline Homosexual & $25(32.05)$ & $12(35.29)$ & \\
\hline Heterosexual & $9(11.54)$ & $1(2.94)$ & \\
\hline Intravenous drug & $1(1.28)$ & 0 & \\
\hline Blood transfusion & $3(3.85)$ & $1(2.94)$ & \\
\hline Unknown & $40(51.28)$ & $20(58.82)$ & \\
\hline Leukocyte count $\left(\times 10^{9} / \mathrm{L}\right)$, median (IQR) & $5.50(3.64,8.57)$ & $4.52(3.20,6.85)$ & 0.22 \\
\hline Neutrophil percentage(\%), median (IQR) & $79.39(61.08,86.42)$ & $68.15(56.18,79.50)$ & 0.01 \\
\hline Lymphocyte percentage (\%), median (IQR) & $11.91(8.48,19.54)$ & $18.20(12.10,27.24)$ & 0.02 \\
\hline CRP (mg/L), median (IQR) & $12.65(3.40,36.23)$ & $13.30(2.70,35.23)$ & 0.75 \\
\hline HIV viral load $\log _{10}($ copy/ml), median (IQR) & $5.50(5.17,5.93)$ & $5.19(4.51,5.67)$ & 0.02 \\
\hline 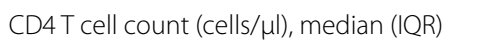 & $22(9,47.75)$ & $22.50(13,77)$ & 0.28 \\
\hline 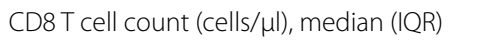 & $458(329.75,679)$ & $485.50(323.75,779.50)$ & 0.54 \\
\hline CD4/CD8 ratio (\%), median (IQR) & $0.05(0.02,0.10)$ & $0.06(0.02,0.16)$ & 0.48 \\
\hline
\end{tabular}

PJP Pneumocystis jirovecii pneumonia, CMV-P cytomegalovirus pneumonia, CRP C-reactive protein, IQR interquartile range, SD standard deviation 
counts $(P=0.54)$, and $\mathrm{CD} 4 / \mathrm{CD} 8$ ratio $(P=0.48)$ between two cohorts.

\section{CT features between PJP and CMV-P}

Thoracic CT features of the 112 patients are shown in Tables 2 and 3. There was no significant difference between PJP and CMV-P in the time between clinical onset and CT examination (6 days in PJP and 5 days in CMV-P, $P=0.99$ ), as well as the time between CT and bronchoscopy (5 days in PJP and 3.50 days in CMV-P, $P=0.07)$. GGO was common in AIDS patients with PJP and CMV-P (Figs. 1a and 2a), with $100 \%$ penetrance in both cohorts. Contrastingly, the frequency of cavity was rare in PJP (2.56\%) and CMV-P (0\%). No significant differences were found in mosaic perfusion, crazy-paving pattern, TIB, bronchial wall thickening, reticulation, LN enlargement, cavity, and cyst between both cohorts (all $P>0.05$ ). As shown in Table 3, the frequency of consolidation and nodules were significantly higher in patients with CMV-P than in those with PJP $(P=0.01$ and $P<0.001$, respectively) (Fig. $1 \mathrm{a}, \mathrm{b}$ and Fig. $2 \mathrm{~b}, \mathrm{c}$ ).

\begin{tabular}{|c|c|c|c|}
\hline & $\mathrm{PJP}(n=78)$ & CMV-P $(n=34)$ & $P$-value \\
\hline $\begin{array}{l}\text { Time between clinical onset } \\
\text { and CT examination (days), } \\
\text { median (IQR) }\end{array}$ & $6(3,10)$ & $5(3,13.25)$ & 0.99 \\
\hline $\begin{array}{l}\text { Time between CT and bron- } \\
\text { choscopy (days), median } \\
\text { (IQR) }\end{array}$ & $5(3,7)$ & $3.50(2,6)$ & 0.07 \\
\hline GGO, $n(\%)$ & 100 & 100 & NS \\
\hline Mosaic perfusion, $n(\%)$ & $25(32.05)$ & $10(29.41)$ & 0.78 \\
\hline Crazy-paving pattern, $n$ (\%) & $7(8.97)$ & $3(8.82)$ & 0.98 \\
\hline $\begin{array}{l}\text { Cons/GGO predominance, } \\
n(\%)\end{array}$ & & & 0.82 \\
\hline Cons & $2(2.56)$ & $2(5.88)$ & \\
\hline GGO & $75(96.15)$ & $32(94.12)$ & \\
\hline Equal & $1(1.28)$ & 0 & \\
\hline Cons/GGO distribution, $n$ (\%) & & & 0.06 \\
\hline Segmental & $6(7.69)$ & $5(14.71)$ & \\
\hline Non-segmental & $6(7.69)$ & $7(20.59)$ & \\
\hline Lobular & $66(84.62)$ & $22(64.71)$ & \\
\hline $\mathrm{TIB}, n(\%)$ & $5(6.41)$ & $5(14.71)$ & 0.16 \\
\hline Bronchial wall thickening, $n(\%)$ & $27(34.62)$ & $16(47.06)$ & 0.21 \\
\hline Reticulation, $n(\%)$ & $45(57.69)$ & $18(52.94)$ & 0.64 \\
\hline LN enlargement, $n(\%)$ & $5(6.41)$ & $5(14.71)$ & 0.16 \\
\hline Pleural effusion, $n(\%)$ & $8(10.26)$ & $8(23.53)$ & 0.07 \\
\hline Cavity, $n(\%)$ & $2(2.56)$ & 0 & 0.35 \\
\hline Cyst, $n(\%)$ & $13(16.67)$ & $4(11.76)$ & 0.51 \\
\hline
\end{tabular}

IQR interquartile range, PJP Pneumocystis jirovecii pneumonia, CMV-P cytomegalovirus pneumonia, $G G O$ ground-glass opacity, Cons consolidation, TIB tree-in-bud sign, LN lymph node, NS no significance
Table 3 Thoracic CT features with significant differentiating frequency

\begin{tabular}{|c|c|c|c|}
\hline & PJP $(n=78)$ & CMV-P $(n=34)$ & $P$-value \\
\hline Nodule, $n(\%)$ & $7(8.97)$ & $16(47.06)$ & $<0.001$ \\
\hline Nodule-size, $n(\%)$ & & & $<0.001$ \\
\hline Micro & $1(1.28)$ & $5(14.71)$ & \\
\hline Small & $5(6.41)$ & $11(32.35)$ & \\
\hline Large & $1(1.28)$ & 0 & \\
\hline Nodule-distribution, $n$ (\%) & & & $<0.001$ \\
\hline Centrilobular & $3(3.85)$ & $8(23.53)$ & \\
\hline Perilymphatic & $1(1.28)$ & 0 & \\
\hline Random & $3(3.85)$ & $8(23.53)$ & \\
\hline Consolidation, n (\%) & $28(35.90)$ & $21(61.77)$ & 0.01 \\
\hline Halo sign, $n(\%)$ & $9(11.54)$ & $11(32.35)$ & 0.01 \\
\hline
\end{tabular}

Data are presented as numbers of patients, with percentages in parentheses PJP Pneumocystis jirovecii pneumonia, CMV-P cytomegalovirus pneumonia

Compared to patients with PJP, large nodules with perilymphatic distribution were not found in any of patients with CMV-P. In addition, halo sign was more frequent in CMV-P (32.35\%) than in PJP (11.54\%). To identify the significant parameters that distinguished PJP from CMV$\mathrm{P}$, binary logistic regression analyses were conducted and 2 significant parameters were identified: consolidation $(P=0.020$; OR: 3.015 ; 95\% CI: $1.190-7.637)$ and nodules $(P<0.001 ;$ OR: 9.298; 95\% CI: 3.191-27.095) (Table 4). Combining consolidation and nodules, the AUC for distinguishing PJP from CMV-P was 0.769.

\section{Correlation analysis of nodules' occurrence between PJP and CMV-P patients}

We next performed correlation analysis of nodules' and consolidations' occurrence between PJP and CMV-P patients (Table 5). Results showed that nodules' occurrence were positively correlated with $\mathrm{CD} 4^{+} \mathrm{T}$ cell count, $\mathrm{CD} 8^{+} \mathrm{T}$ cell count and $\mathrm{CD} 4 / \mathrm{CD} 8$ ratio, while no significant correlations were found with CRP, neutrophil percentage and HIV viral load in CMV-P patients. Among patients with PJP, no significant correlations were observed between nodules' occurrence or any other clinical indicators. Similarly, there were no significant correlations between consolidations' occurrence and other clinical indicators in PJP and CMV-P patients (Additional file 1: Table S1).

\section{Discussion}

PJP and CMV-P are two of the most common infectious pathogens in AIDS patients leading to life-threatening pneumonia. In terms of baseline characteristics of enrolled patients, this study shows that CD4 T lymphocyte counts of PJP group and CMV-P group were both 

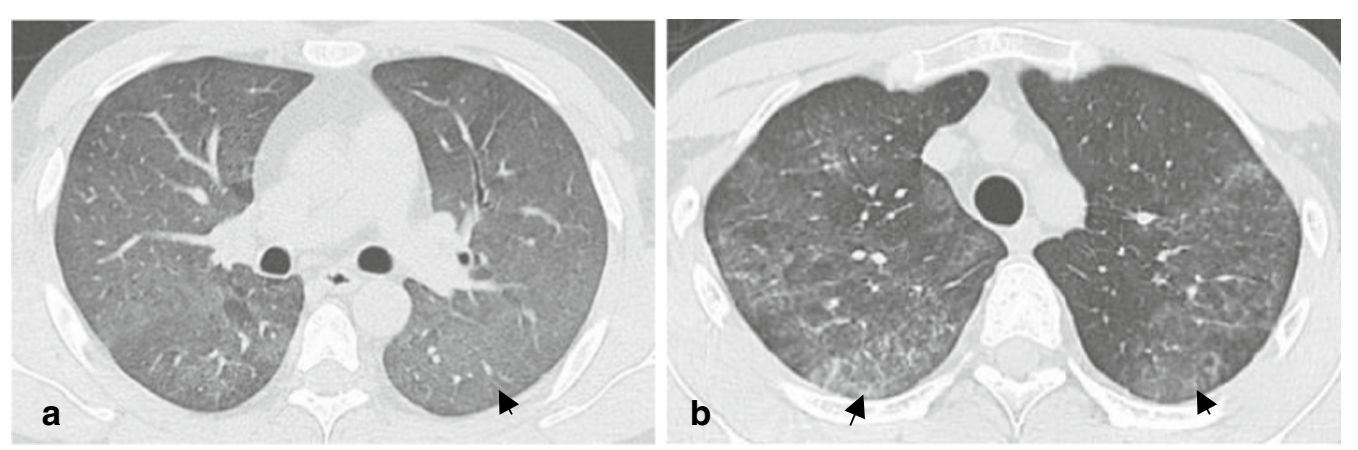

Fig. 1 Pneumocystis jirovecii pneumonia. a Pneumonia caused by P.jirovecii in a 28-year-old male patient with AIDS. HRCT image showed diffuse ground-glass opacity of bilateral pulmonary parenchyma (arrow). b Pneumonia caused by P. jirovecii in a 31-year-old male patient with AIDS. HRCT image showed multiple ground-glass opacity of bilateral pulmonary parenchyma with reticulate changes (arrows)
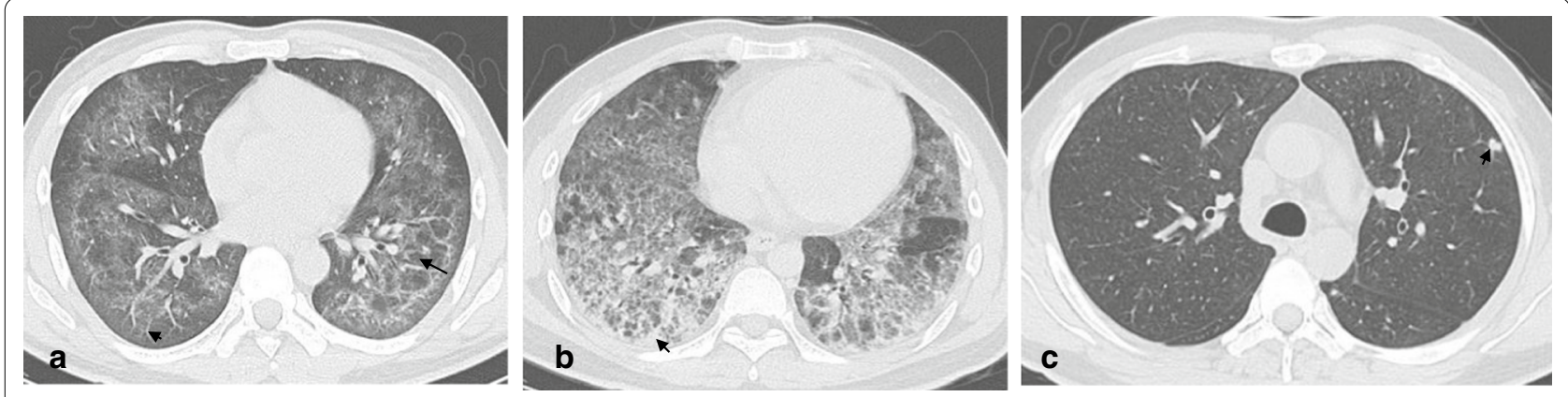

Fig. 2 Cytomegalovirus pneumonia. a Pneumonia caused by cytomegalovirus in a 38-year-old male patient with AIDS. HRCT image showed ground-glass opacity, reticulation (arrow), and mosaic perfusion (long arrow). b Pneumonia caused by cytomegalovirus in a 36-year-old male patient with AIDS. HRCT image showed ground-glass opacity, reticulation, consolidation (arrow), and mosaic perfusion. c Pneumonia caused by cytomegalovirus in a 29-year-old male patient with AIDS. HRCT image showed ground-glass opacity, nodules with halo sign (arrow) and tree in bud sign

Table 4 The results of binary logistic regression analysis

\begin{tabular}{lcclll}
\hline HRCT features & B value & Wald value & Odds ratio & P-value & 95\% Cl \\
\hline Nodules & 2.230 & 16.696 & 9.298 & 0.001 & $3.191-27.095$ \\
Consolidation & 1.104 & 5.417 & 3.015 & 0.020 & $1.190-7.637$ \\
constant & -1.919 & 24.951 & 0.147 & 0.001 & 0.769 \\
\hline
\end{tabular}

HRCT high-resolution computed tomography, $\mathrm{Cl}$ confidence intervals, $A U C$ area under the receiver operating

lower than 50 cells $/ \mathrm{mm}^{3}$, highlighting the importance of cell-mediated immunodeficiency for the development of PJP and CMV-P. Here neutrophil percentage in PJP was higher than CMV-P. These may be correlated with an increase of inflammatory cytokines and use of corticosteroid in patients with PJP, that might promote neutrophils recruitment and granulopoiesis [18]. Additionally, lymphocyte percentage in CMV-P patients was higher than that of PJP, which may result from higher HIV viral loads in CMV-P group than that in PJP group.
Here we observed several similarities in radiological presentations between two types of pneumonia. The frequency of GGO were highly common, while the occurrence of cavity was relatively rare in both cohorts. Furthermore, both PJP and CMV-P patients showed similar frequency of reticulation, bronchial wall thickening, mosaic perfusion, cyst, crazy-paving pattern, TIB, and LN enlargement. Diffuse alveolar damage might be the main reason for these similarities $[19,20]$. 
Table 5 Correlation analysis of nodules' occurrence between pneumocystis pneumonia and cytomegalovirus pneumonia patients

\begin{tabular}{|c|c|c|c|c|}
\hline \multirow[t]{2}{*}{ Variable } & \multicolumn{2}{|c|}{$\mathrm{PJP}(n=78)$} & \multicolumn{2}{|c|}{ CMV-P $(n=34)$} \\
\hline & R-value & $P$-value & R-value & $P$-value \\
\hline $\mathrm{CD}^{+}{ }^{+} \mathrm{T}$ cell count & 0.159 & 0.163 & 0.545 & 0.001 \\
\hline $\mathrm{CD}^{+}{ }^{+} \mathrm{T}$ cell count & 0.111 & 0.332 & 0.392 & 0.022 \\
\hline CD4/CD8 ratio & 0.104 & 0.366 & 0.503 & 0.002 \\
\hline CRP & -0.059 & 0.607 & 0.182 & 0.304 \\
\hline Neutrophil percentage & 0.02 & 0.859 & -0.233 & 0.186 \\
\hline HIV viral load $\log _{10}$ & 0.08 & 0.488 & -0.27 & 0.122 \\
\hline
\end{tabular}

PJP Pneumocystis jirovecii pneumonia, CMV-P pneumocystis pneumonia, CRP C-reactive protein

In contrast, the occurrence of consolidation, nodules, and the halo sign was more common in CMV-P than in PJP patients. In addition, large nodules with perilymphatic distribution were not found in any of CMV-P patients. The nodules' occurrence were positively correlated with $\mathrm{CD}^{+} \mathrm{T}$ cell count, $\mathrm{CD}^{+} \mathrm{T}$ cell count and CD4/CD8 ratio in CMV-P patient, while no significant correlations were found in PJP patients. These differences in radiological presentations might result from intrinsic virulence factors and immune responses to these pathogens. Human cytomegalovirus belongs to the herpesvirus subfamily, with seroprevalence of $40-100 \%$ in the world's population [5, 21]. Cytomegalovirus can establish life-long latent infection and reactivate during episodes of immunosuppression [22]. Despite eliciting strong and long-lasting immune responses, these antiviral immune responses cannot clear the virus entirely, nor can they effectively prevent superinfection with additional cytomegalovirus strains or reactivation of the persisting viruses. Hence, alterations in host immunity, such as HIV co-infection, tend to allow for increased virus replication and disease progression [5]. P. jirovecii is an extracellular fungus that almost exclusively inhabits alveolar spaces [23], causing pulmonary infection through adhesion to the surface of alveolar epithelium cells (type I pneumocytes) [24]. A normal immune response is sufficient to clear $P$. jirovecii infection in most people without any evidence of latent infection [23]. Moreover, P. jirovecii has a unique tropism for the lung, where it exists primarily as an alveolar pathogen without systemic dissemination. Therefore $P$. jirovecii adherence to alveolar epithelium cannot justify such diffuse alveolar damage observed during severe pneumonia. Rather, the patient's inflammatory response is the primary driver of such extensive alveolar-capillary surface damage [25]. Granulomas are rare in patients with $P$. jirovecii infection, but have been described before [26]. Taken together, these mechanisms induce alterations in host histopathology, which in turn allow for radiological differences between these two diseases.

There are several limitations in present study. The single-centre design may hamper the generalization of our conclusions. Patients included were in different stages of diseases, since BAL results was used as diagnostic criteria, which might influence the frequency of CT features, such as halo signs and cavities; and the lack of histological specimens limited the analysis of correlation with pathologic radiology. In addition, sensitivity and specificity of these patterns in AIDS patients requires further validation in a blinded retrospective or future prospective study.

\section{Conclusions}

The occurrence of consolidation, micro and small nodules with centrilobular or random distribution, and halo sign were highly suggestive of CMV-P rather than PJP in AIDS patients. The GGO, reticulation, and bronchial wall thickening were found with similar occurrence in both pneumonia and, hence, cannot distinguish these two diseases. CT features are potentially useful for the differential diagnosis of pneumocystis pneumonia and cytomegalovirus pneumonia in AIDS patients.

\section{Supplementary information}

Supplementary information accompanies this paper at https://doi. org/10.1186/s40249-020-00768-2.

Additional file 1: Table S1. Correlation analysis of consolidations' occurrence between pneumocystis pneumonia and cytomegalovirus pneumonia patients.

\section{Abbreviations}

AIDS: Acquired immunodeficiency syndrome; AUC: Area under the receiver operating; BAL: Bronchoalveolar lavage; Cl: Confidence intervals; CMV-P: Cytomegalovirus pneumonia; GGO: Ground-glass opacity; HRCT: High-resolution computed tomography; LN: Lymph node; PCP: Pneumocystis pneumonia; PJP: Pneumocystis jirovecii Pneumonia; TIB: Tree-in-bud sign.

\section{Acknowledgements}

The authors gratefully acknowledge Liu-Luan Zhu Ph.D., and Hui Zeng Ph.D. for their assistance with experiments designed, as well as Gang Wan Ph.D. and Jun-Nan Li Ph.D. for their assistance with data analysis.

\section{Authors' contributions}

$A L$ and B-DC designed the experiments. C-JD, AL, B-DC, J-YL, HC, LP, R-M, X, and $M Z g$ performed the experiments: $C-J D, A L$, and B-DC analyzed the data. C-JD, AL, and B-DC supplied materials and analysis tools. C-JD, AL, and B-DC wrote the paper. All authors read and approved the final manuscript.

\section{Funding}

This study was financially supported by Beijing Municipal Administration of Hospitals Clinical Medicine Development China (Grant No: ZYLX201802).

Availability of data and materials

Data of this study can be available upon request from the author. 


\section{Ethics approval and consent to participate}

This clinical study was conducted in compliance with the ethical principles of the Declaration of Helsinki and its later amendments. The Ethics Committee of Beijing Ditan Hospital approved our study protocol [Approval No. NA2018(005)-01]. As a de-identified retrospective study, the ethics committee did not require us to obtain written or verbal informed consent from participants.

\section{Consent for publication}

Not applicable.

\section{Competing interests}

The authors declare that they have no competing interests.

Received: 11 June 2020 Accepted: 19 October 2020

Published online: 26 October 2020

\section{References}

1. Bhutta ZA, Sommerfeld J, Lassi ZS, Salam RA, Das JK. Global burden, distribution, and interventions for infectious diseases of poverty. Infect Dis Poverty. 2014;3:21

2. Knoblauch AM, Divall MJ, Owuor M, Nduna K, Ng'Uni H, Musunka G, et al. Experience and lessons from health impact assessment guiding prevention and control of HIV/AIDS in a copper mine project, northwestern Zambia. Infect Dis Poverty. 2017;6(1):114.

3. Joint United Nations Programme on HIV/AIDS. AIDS BY THE NUMBERS. https://www.unaids.org/en.

4. McKinnell JA, Cannella AP, Kunz DF, Hook ER, Moser SA, Miller LG, et al. Pneumocystis pneumonia in hospitalized patients: a detailed examination of symptoms, management, and outcomes in human immunodeficiency virus (HIV)-infected and HIV-uninfected persons. Transpl Infect Dis. 2012;14(5):510-8.

5. Fonseca Brito L, Brune W, Stahl FR. Cytomegalovirus (CMV) pneumonitis: Cell tropism, inflammation, and immunity. Int J Mol Sci. 2019;20(16):3865.

6. Gigliotti F, Wright TW. Pneumocystis: where does it live? Plos Pathog. 2012;8(11):e1003025.

7. Sepkowitz KA. Opportunistic infections in patients with and patients without acquired immunodeficiency syndrome. Clin Infect Dis. 2002;34(8):1098-107.

8. Nichols WG, Boeckh M. Recent advances in the therapy and prevention of CMV infections. J Clin Virol. 2000;16(1):25-40.

9. Cooley L, Dendle C, Wolf J, Teh BW, Chen SC, Boutlis C, et al. Consensus guidelines for diagnosis, prophylaxis and management of Pneumocystis jirovecii pneumonia in patients with haematological and solid malignancies, 2014. Intern Med J. 2014;44(12b):1350-63.

10. Doyle L, Vogel S, Procop GW. Pneumocystis PCR: it is time to make PCR the test of choice. Open Forum Infect Dis. 2017;4(4):x193.

11. Procop GW, Haddad S, Quinn J, Wilson ML, Henshaw NG, Reller LB, et al. Detection of Pneumocystis jirovecii in respiratory specimens by four staining methods. J Clin Microbiol. 2004;42(7):3333-5.
12. Ljungman $\mathrm{P}$, Boeckh M, Hirsch HH, Josephson F, Lundgren J, Nichols G, et al. Definitions of cytomegalovirus infection and disease in transplant patients for use in clinical trials. Clin Infect Dis. 2017;64(1):87-91.

13. Razonable RR, Hayden RT. Clinical utility of viral load in management of cytomegalovirus infection after solid organ transplantation. Clin Microbiol Rev. 2013;26(4):703-27.

14. Chuganji E, Abe T, Kobayashi H, Nakano N, Kanai T, Ohara G, et al. Fatal pulmonary co-infection with pneumocystis and cytomegalovirus in a patient with acquired immunodeficiency syndrome. Internal Med. 2014;53(14):1575-8

15. Cereser L, Dallorto A, Candoni A, Volpetti S, Righi E, Zuiani C, Girometti R. Pneumocystis jirovecii pneumonia at chest high-resolution computed tomography (HRCT) in non-HIV immunocompromised patients: Spectrum of findings and mimickers. Eur J Radiol. 2019;116:116-27.

16. Hansell DM, Bankier AA, MacMahon H, McLoud TC, Muller NL, Remy J. Fleischner Society: glossary of terms for thoracic imaging. Radiology. 2008;246(3):697-722.

17. Wormanns D, Hamer OW. Glossary of terms for thoracic imagingGerman version of the Fleischner Society recommendations. Rofo. 2015;187(8):638-61.

18. Youssef J, Novosad SA, Winthrop KL. Infection risk and safety of corticosteroid use. Rheum Dis Clin N Am. 2016;42(1):157-76.

19. Kayik SK, Acar E, Memis L. Pneumocystis jirovecii pneumonia in newly diagnosed HIV infection: A challenging case report. Turk Patoloji Derg. 2020;1:1.

20. McGuinness G, Scholes JV, Garay SM, Leitman BS, McCauley DI, Naidich DP. Cytomegalovirus pneumonitis: spectrum of parenchymal CT findings with pathologic correlation in 21 AIDS patients. Radiology. 1994;192(2):451-9.

21. Omeri AK, Okada F, Takata S, Ono A, Nakayama T, Ando Y, et al. Comparison of high-resolution computed tomography findings between Pseudomonas aeruginosa pneumonia and cytomegalovirus pneumonia. Eur Radiol. 2014;24(12):3251-9.

22. Lee HS, Park JY, Shin SH, Kim SB, Lee JS, Lee A, Ye BJ, Kim YS. Herpesviridae viral infections after chemotherapy without antiviral prophylaxis in patients with malignant lymphoma: incidence and risk factors. Am J Clin Oncol. 2012;35(2):146-50.

23. Skalski JH, Kottom TJ, Limper AH. Pathobiology of pneumocystis pneumonia: life cycle, cell wall and cell signal transduction. Fems Yeast Res. 2015;15:6.

24. Avino LJ, Naylor SM, Roecker AM. Pneumocystis jirovecii pneumonia in the non-HIV-infected population. Ann Pharmacother. 2016;50(8):673-9.

25. Thomas CJ, Limper AH. Pneumocystis pneumonia. N Engl J Med. 2004;350(24):2487-98.

26. Roden AC, Schuetz AN. Histopathology of fungal diseases of the lung. Semin Diagn Pathol. 2017;34(6):530-49.

\section{Publisher's Note}

Springer Nature remains neutral with regard to jurisdictional claims in published maps and institutional affiliations.

\footnotetext{
Ready to submit your research? Choose BMC and benefit from:

- fast, convenient online submission

- thorough peer review by experienced researchers in your field

- rapid publication on acceptance

- support for research data, including large and complex data types

- gold Open Access which fosters wider collaboration and increased citations

- maximum visibility for your research: over $100 \mathrm{M}$ website views per year
}

At BMC, research is always in progress.

Learn more biomedcentral.com/submissions 